\title{
Das fintas ao tributo: a trajetória da Contribuição de Melhoria no Brasil
}

\author{
From fintas to tribute: a path of the Betterment Levy in Brazil
}

Gislene Pereira

Arquiteta e urbanista, doutora em Meio Ambiente e Desenvolvimento pela Universidade Federal do Paraná (UFPR),

Curitiba - PR, Brasil, e-mail: gislenepereira42@gmail.com

\section{Resumo}

O interesse pela discussão sobre instrumentos para gestão social da valorização da terra vem crescendo nas administrações municipais, que identificam na temática a possibilidade de encontrar caminhos alternativos para financiar o desenvolvimento urbano, especialmente num contexto de redução das tradicionais fontes de recursos. Incluído no Estatuto da Cidade (Lei Federal n. 10.257/01) como instrumento de política urbana, a Contribuição de Melhoria consiste em uma modalidade tributária que possibilita ao Poder Público recuperar a expressão financeira da valorização imobiliária decorrente da realização de obras públicas. A origem desse tributo remonta às Ordenações Filipinas, que autorizavam a cobrança de fintas, para obter recursos para reconstruir pontes e calçadas. As Ordenações Filipinas vigoraram em Portugal de 1603 a 1867, e constituíram a base da legislação no Brasil Colônia, sendo substituídas somente em 1916 pelos Códigos Civil e Penal da República. A Contribuição de Melhoria foi institucionalizada no Brasil como tributo pela Constituição de 1934, que passou a exigir sua cobrança em obras públicas que valorizassem imóveis adjacentes a elas. Legislações subsequentes à Constituição de 1934 (Constituição 1946, Código Tributário Nacional, 1966, Constituição 1988), modificaram o conceito inicial, sendo criado um tributo sui generis, especificamente brasileiro. A partir da apresentação da trajetória da institucionalização da Contribuição de Melhoria no Brasil, pretende-se reconhecer os conceitos originados das normas portuguesas, bem como de outras interferências internacionais, delineando-se, assim, as especificidades desse tributo no país.

Palavras-chave: Recuperação mais-valia. Contribuição de melhoria. Gestão urbana.

\section{Abstract}

The interest in discussion of tools for value capture grows in municipal administrations, which identify the possibility to find alternative to finance urban development, especially in the context of reducing of traditional funding sources. Included in the City Statute (Federal Law n. 10.257/01) as an instrument of urban policy, the Betterment Levy consists of a tax that allows the Government to recover the financial expression of the increase of land values resulted from public interventions. The origin of this tax goes back to the Philippines Ordinances, 
which authorized the fintas, to raise funds to rebuild bridges and sidewalks. Ordinations Philippines prevailed in Portugal from 1603 to 1867, and formed the basis of legislation in Brazil, only being replaced in 1916 by the Civil and Penal Codes of the Republic. The Betterment Levy was institutionalized in Brazil by the Constitution of 1934, which required its collection in public interventions. Laws after Constitution 1934, modified the initial concept, and created a tribute sui generis, specifically Brazilian. From the discussion of the institutionalization of Betterment Levy in Brazil, this paper aims to recognize the concepts originated from Portuguese laws, as well as other international interference, outlining the specificities of this tax in the country.

keywords: Value capture. Betterment levy. Urban management.

\section{Introdução}

Instrumento legal e constitucional de recuperação de ganhos com valorização imobiliária, a Contribuição de Melhoria constitui-se numa

espécie de tributo cujo fato gerador é a valorização de imóvel do contribuinte, decorrente de obra pública, e tem por finalidade a justa distribuição dos encargos públicos, fazendo retornar do tesouro público o valor despendido com a realização de obras públicas, na medida em que destas decorra valorização de imóveis (MACHADO, 2007, p. 455).

O tributo é aplicado em diversos países, como Colômbia (Contribución de valorización0), Inglaterra (Betterment tax), Estados Unidos (Special assessment), França (Contribution sur les plus values), Itália (Contributi di meglioria) e Espanha (Contribución de mejoras), e de diferentes maneiras (SILVA, 2001).

No Brasil, é um tributo de competência não só municipal, mas também estadual e federal, nos termos do que estabelece o artigo 145, III da Constituição Federal de 1988, artigos 81 e 82 do Código Tributário Nacional e Decreto-Lei n. 195/67.

Conforme a regulamentação jurídica estabelece, a Contribuição de Melhoria é um tributo indiretamente vinculado a uma atuação estatal e deverá ser cobrado sempre que uma obra pública gerar valorização imobiliária. A cobrança deverá ocorrer após a conclusão da obra e tem como limite de valor o custo dela, associado à valorização auferida pelos imóveis beneficiados por ela.

\section{Das fintas ao tributo: uma assimilação de ideias e princípios}

A mais antiga formatação de um tributo nos moldes da Contribuição de Melhoria remonta ao século XIII, na Inglaterra. Em 1250, para atender às despesas de retificação e saneamento do Rio Tâmisa, a Câmara dos Lordes estabeleceu a cobrança de um tributo sobre os imóveis atingidos diretamente pelas obras (SANTIAGO, 2012). Entendeu-se que não seria justo que a sociedade em geral arcasse com a totalidade dos custos, sendo que os imóveis lindeiros à obra eram os principais beneficiados, auferindo valorização imediata. Nesse modelo inglês, verifica-se a relação entre a utilização do tributo e o reconhecimento da valorização ocasionada pela realização de uma obra pública.

Em 1296, um tributo semelhante era utilizado na Itália. Na cidade de Florença, foi cobrada contribuição dos proprietários lindeiros, para viabilizar a ampliação da praça onde se encontravam o Batistério de San Giovanni e a igreja de Santa Reparata (SANTIAGO, 2012).

Em 1691, a Câmara legislativa de Nova York criou o special assessment, que é uma modalidade de contribuição de melhoria aplicável a todos os tipos de obra pública (SANTIAGO, 2012). Outra referência histórica de utilização da Contribuição de Melhoria vem da Prússia, em 1875, onde o tributo foi aplicado para compensar gastos com obras públicas.

A origem do tributo no Brasil remonta às Ordenações Filipinas, conjunto de leis promulgadas em 1603 por Filipe I, rei de Portugal. Da descoberta, em 1500, até a proclamação da independência brasileira, em 1822, as Ordenações regeram 
o ordenamento jurídico no Brasil. Após a proclamação da independência, uma lei editada em 1823 determinou a manutenção das Ordenações Filipinas no Brasil. Em 1824, a Constituição do Império estabeleceu que deveriam ser organizados os códigos civil e criminal; entretanto, somente em 1916 foi promulgado o Código Civil e Penal da República do Brasil. Ou seja, por mais de 300 anos, o direito brasileiro constituiu-se em simples extensão dos direitos da coroa portuguesa, sendo definido pelas Ordenações do Reino de Portugal.

As Ordenações Filipinas são constituídas por cinco livros, cujos títulos dos capítulos permitem visualizar como era a organização social e econômica da época, tanto em Portugal como nas colônias portuguesas. Alguns exemplos de capítulos das Ordenações:

Título XIV: Dos que publicam Inibitórias sem licença de El Rei;

Título XXXV: Da maneira, que se terá na sucessão das terras, e bens da Coroa do Reino;

Título XXXVII: Das mulheres, que têm coisas da Coroa do Reino, e se casam sem licença do Rei;

Título LV: Das pessoas, que devem ser havidas por naturais destes reinos;

Título VII: Dos que dizem mal do Rei;

Título LXVI: Dos Mercadores que quebram: E dos que se levantam com fazenda alheia;

Título CXII: Das coisas, que se não podem levar fora do reino sem licença do Rei (ORDENAÇÕES FILIPINAS, 2012, p. 1).

As influências do ordenamento jurídico português no Brasil podem ser identificadas pela permanência até a atualidade de alguns conceitos e princípios. A assimilação de ideias legislativas portuguesas justifica, por exemplo, a conformação de alguns tributos ainda hoje vigentes no país.

Este estudo associa as origens do tributo Contribuição de Melhoria ao sistema de fintas, que eram encargos pecuniários passíveis de serem cobrados pela Coroa portuguesa, para custeio de certas obras públicas, como pontes, fontes e calçadas.

O Livro 1 Título LVI das Ordenações estabelece:
40. E porque muitas vezes as rendas do Concelho não bastam para as cousas que os Officiaes das Cameras são obrigados por seus Regimentos prover e fazer, mandamos que quando lhes parecer lançar finta, e não houver para ellas dinheiro do Concelho, o escrevam ao Corregedor da Comarca, como a querem pedir, declarando para que cousas e a necessidade que dela tem (ORDENAÇÕES FILIPINAS, 2012, p. 151, grifo nosso).

E o Título LVIII complementa, associando as fintas à realização de obras:

42. E achando na sua correição ${ }^{1}$ alguns lugares despovoados, saberá por que se despovoaram, e por que modo se melhor poderão povoar. E faça-o saber a Nós, para mandarmos o que for nosso serviço. 43. E mandará que se façam as benfeitorias públicas, calçadas, pontes, fontes, poços, chafarizes, caminhos, casas do Concelho, picotas e outras benfeitorias, que forem necessárias, mandando logo fazer as que cumprir de novo serem feitas, e reparar as que houverem mister reparo: o que todo fará das rendas do Concelho. E sendo os danificamentos por negligência dos Vereadores, os fará emendar por seus bens. E quando não houver dinheiro do Concelho, e houver necessidade de finta para o dito caso, ou para outros, que lhe pareçam necessários, poderá mandar fintar até quantia de quatro mil réis. E sendo necessário mais, no-lo fará saber, para Nós lhe darmos a provisão, que nos bem parecer, sem a qual em nenhum caso dará licença para fintar (ORDENAÇÕES FILIPINAS, 2012, p. 109, grifo nosso).

Obedecendo às normativas das Ordenações, o Brasil adotou o sistema de fintas para conseguir recursos financeiros para realização de obras públicas. As primeiras iniciativas nacionais de aplicação das fintas ocorreram em 1812, em Jaguaribe, então Bahia, para calçamento de vias urbanas; e em 1818, em Mariana, Minas Gerais, para recuperação de pontes (SANTIAGO, 2012).

Posteriormente, o princípio legal do sistema de cobrança de fintas foi utilizado para dedução da

\footnotetext{
1 O corregedor era o magistrado administrativo e judicial que representava a Coroa em cada uma das comarcas de Portugal. A ação exercida por ele na sua comarca era designada por correição, termo que também podia ser sinônimo da própria comarca.
} 
valorização imobiliária do montante de indenização a ser pago pelo governo, no caso de desapropriações de interesse público. 0 Decreto n. 816, de 1825, determinava a dedução do "quantum indenizatório da valorização ocasionada pela obra pública sobre o restante da propriedade" (SANTIAGO, 2012, p. 1). Essa normativa foi sucedida pelo Decreto Imperial n. 1.664, de 1855 e, posteriormente, pela lei n. 1021, de 1903, a qual orientou os processos de desapropriações realizados para a construção da atual Av. Rio Branco, na cidade do Rio de Janeiro.

Em 1932, o Decreto n. 21.390, regulamentava a criação, pelos estados e municípios, da taxa especial de benefício. Diz o decreto:

O Chefe do Governo Provisório da República dos Estados Unidos do Brasil:

Considerando que o desenvolvimento das cidades modernas implica, para que sejam dotadas do indispensável conforto e suficientemente aparelhadas de acordo com as exigências sempre crescentes da vida coletiva, despesas que excedem as possibilidades da caixa comum ou da receita geral do Estado ou do município;

Considerando que, nesses termos, é hoje princípio corrente de administração municipal que todo serviço de caráter local, produzindo benefícios locais ou restritos a uma determinada zona, deve ser custeado por uma taxa local especial ou de benefício, paga pelos direta ou indiretamente beneficiados e cujo produto corresponda ao custo do serviço;

[...] decreta:

Art. 1ํ É facultado aos Estados criar taxas especiais destinadas à execução de obras e serviços públicos de caráter local, produzindo benefícios locais ou restritos a uma determinada zona, com incidência sobre pessoas ou bens direta ou indiretamente beneficiados (BRASIL, 1932).

A Contribuição de Melhoria foi institucionalizada como tributo no Brasil pela Constituição de 1934, que exigia sua cobrança em obras públicas que valorizassem imóveis adjacentes a elas. A Constituição definia:

Artigo 124. Provada a valorização do imóvel por motivo de obras públicas, a administração que as tiver efetuado poderá cobrar dos beneficiados Contribuição de Melhoria (BRASIL, 1934).
Legislações subsequentes à Constituição de 1934 (Constituição 1946, Código Tributário Nacional de 1966, Constituição 1988) modificaram o conceito inicial, sendo adicionados aspectos da legislação alemã e americana, conformando-se um instituto jurídico especificamente brasileiro. De fato, a utilização do tributo na Inglaterra e Alemanha obedece a modelos diferenciados, que influenciaram a organização da legislação contemporânea sobre Contribuição de Melhoria no Brasil. No modelo inglês, verifica-se uma relação entre a utilização do tributo e o reconhecimento da valorização ocasionada pela realização de uma obra pública. No modelo alemão, a contribuição de Melhoria é utilizada para recuperação de gastos públicos já efetuados, tendo como princípio a repartição de custos sociais - o custo da obra é rateado entre os beneficiários dela. Como coloca Bittencourt:

0 primeiro modelo tem como fundamento a equidade, determinando os contribuintes e a base de cálculo conforme a valorização individual de seus imóveis, já na visão germânica o que se leva em consideração é o gasto público, ou seja, o beneficio não é tomado como base de cálculo; o tributo destina-se a recuperar todo gasto estatal, decorrente da realização da obra pública (BITTENCOURT, 2012, p. 3).

A Contribuição de Melhoria no Brasil adota sistema misto de cobrança, que considera o critério da valorização, mas estabelece como limite máximo de cobrança o custo da obra.

\section{A Contribuição de Melhoria no Brasil e Portugal de hoje: similaridades e diferenças}

Este estudo buscou fazer análise comparativa do processo de cobrança da Contribuição de Melhoria, na atualidade do Brasil e em Portugal. 0 propósito era identificar eventuais similaridades, que permitissem reconhecer a origem comum dos dois processos.

Portugal possui, atualmente, duas denominações para tributos equivalentes à Contribuição de Melhoria brasileira: Encargo de mais valia e Contribuição especial. Diferindo apenas nas situações em que foram aplicados, ambos têm o mesmo 
objetivo da Contribuição de Melhoria: a recuperação para o poder público da valorização auferida por imóveis, decorrentes da realização de obras públicas.

O Quadro 1 apresenta uma comparação entre práticas de utilização de instrumentos de recuperação da valorização imobiliária, no Brasil e Portugal:

A comparação detalhada dos dois processos de cobrança da valorização imobiliária entre Portugal e Brasil dependeria de um estudo mais aprofundado das legislações específicas. Entretanto, o Quadro 1 demonstra que os processos são bastante parecidos, permitindo inferir uma origem comum. A principal diferença está no momento da cobrança do tributo: em Portugal, pode-se cobrar antes ou após a conclusão da obra (padrão existente no antigo sistema de fintas), enquanto no Brasil a cobrança só é permitida após a conclusão da obra.

0 estudo permitiu verificar que a utilização do tributo Contribuição de Melhoria, tanto em Portugal quanto no Brasil, está restrita a poucas obras. Nos dois países, a Contribuição de Melhoria ainda é subutilizada como instrumento para recuperar a valorização gerada pela implementação de obras públicas.

\section{A cobrança de Contribuição de Melhoria no Brasil: por tradição ou por penúria?}

O interesse pela discussão, e utilização, de instrumentos para recuperação social da valorização da terra vem crescendo junto às administrações municipais no Brasil, numa tentativa de buscar caminhos alternativos para financiar o desenvolvimento urbano. 0 baixo nível de investimento público nas últimas décadas no Brasil tem resultado em uma carência generalizada de infraestrutura na maioria das cidades do país. De fato, conforme Vetter (2011), o Banco Mundial estima um atraso, na infraestrutura municipal, de aproximadamente US\$ 40 milhões para os próximos dez anos. Dependentes de transferências do governo federal, os municípios têm tido dificuldades em encontrar outras fontes para obtenção de recursos.

Nesse contexto, a utilização de instrumentos de recuperação de mais-valias urbanas tende a ser considerada como alternativa concreta de acesso a recursos financeiros. No rol desses mecanismos para recuperar, para a coletividade, a valorização imobiliária encontram-se tributos, dispositivos para gestão democrática e instrumentos urbanísticos, descritos no Plano Diretor, bem como regulamentados por legislação específica.

0 conceito presente nesses mecanismos é que determinadas ações e decisões urbanísticas podem incrementar o valor da terra e, sendo essas ações provenientes do poder público, com consequente utilização de recursos públicos, os benefícios também deveriam ser apropriados pela coletividade e não de forma privada. Assim sendo, os benefícios da valorização imobiliária, gerados por ações do poder público, deveriam ser recuperados por ele, redistribuindo os benefícios entre toda a coletividade.

No Brasil, a Lei Federal n. 10.257/01, denominada Estatuto da Cidade, regulamenta, no art. $2^{\circ}$, um conjunto de instrumentos a serem utilizados na "justa distribuição dos bônus da urbanização" (BRASIL, 2001). Um desses instrumentos previstos é a Contribuição de Melhoria, a qual possibilita ao poder público recuperar

Quadro 1 - Mecanismos para recuperação da valorização imobiliária. Portugal e Brasil

\begin{tabular}{|c|c|c|c|c|}
\hline País & Investimento público & Momento de cobrança & Incidência da cobrança do tributo & Legislação regulamentadora \\
\hline \multirow[t]{3}{*}{ PORTUGAL } & Construção de pontes & Anterior e posterior à obra & Proprietários dentro da área de influência da obra & DLn. 46950, de 9/04/1966 \\
\hline & $\begin{array}{l}\text { Construção de vias } \\
\text { de circulação }\end{array}$ & & Proprietários ao longo das vias & DRn. 4, de 25/1/1983 \\
\hline & Obras de urbanização & & Proprietários dentro da área de influência da obra & Lein. 168, de 18/9/1999 \\
\hline \multirow[t]{2}{*}{ BRASIL } & Obras de urbanização & Posterior à conclusão da obra & Proprietários dentro da área de influência da obra & \multirow{2}{*}{$\begin{array}{l}\text { - Constituiccão Federal/ } 1988 \\
\text { - Código Tributário Nacional/67 e } \\
2005 \\
\text { - Decreto Federal n.195/67 } \\
\text { Códigos Tributários Municipais }\end{array}$} \\
\hline & $\begin{array}{l}\text { Abertura e consolidação de } \\
\text { vias de circulação }\end{array}$ & Posterior à conclusão da obra & Proprietários ao longo das vias & \\
\hline
\end{tabular}

Fonte: Elaborada a partir de RIBEIRO, 2005. 
a expressão financeira da valorização imobiliária decorrente da realização de obras públicas.

Originária de legislação estabelecida pela corte portuguesa, conforme já apresentado, a Contribuição de Melhoria, apesar da larga trajetória histórica, vem sendo pouco utilizada no país. Entretanto, é possível verificar crescente interesse na sua aplicação por parte das administrações municipais. Segundo Smolka e Furtado (2005), as principais razões desse interesse seriam:

- a existência de uma demanda crescente por fontes alternativas de recursos para intervenções urbanas, diante da escassez das fontes tradicionais;

- a redefinição das funções do Estado, que oferece possibilidades para ações de planejamento mais flexíveis, com parcerias com o setor privado e a população.

Diante dessa situação, verifica-se que o crescimento da utilização da Contribuição de Melhoria está mais associado a razões eminentemente pragmáticas do que a critérios de ética, princípios de equidade ou justificativas teóricas ou políticas (SMOLKA; FURTADO, 2005).

Essa constatação confirmaria a hipótese segundo a qual a assimilação de ideias (no caso, a cobrança de um tributo),

[...] pode ser potencializada por características do momento de sua(s) formulação(ões): situações políticas, interesses geopolíticos, crises e avanços econômicos, características geográficas, imposições religiosas, disponibilidade de tecnologias [...]

Desta interminável lista de fatores que possam garantir, potencializar ou reduzir o impacto e circulação de uma ideia, muitos autores destacam os fenômenos catastróficos ou de penúria (ULTRAMARI, 2012, p. 9).

Ou seja, no caso em estudo, o crescente interesse pelo tema dos instrumentos para recuperação social da valorização imobiliária, em especial a Contribuição de Melhoria, aparece associado a uma situação de "penúria" das fontes tradicionais de financiamento urbano.

\section{Considerações finais}

Este texto pretendeu identificar a trajetória da institucionalização da Contribuição de Melhoria no Brasil como decorrente da assimilação de ideias e princípios originários de Portugal. Verifica-se que todo o processo de institucionalização do tributo no país teve origem nas Ordenações Filipinas, no período do Brasil Colônia. Desse período para frente, o tributo foi sendo modificado, adaptando-se às transformações do país, bem como às demandas da administração pública.

No processo de assimilação de ideias, como é a incorporação da Contribuição de Melhoria na legislação brasileira, vale lembrar Ultramari (2012), quando destaca a importância de reconhecer as distintas formas pelas quais ideias "viajam". Ultramari coloca que podem ser identificadas duas formas de transmissão de ideias. Em uma primeira forma,

as ideias viajam e são acriticamente replicadas em outros espaços, constituindo um certo difusionismo acrítico, tal qual ocorrem com ex-colônias ou a atual difusão de hegemonias a partir de centros de poder político, econômico e cultural.

No segundo caso, as ideias viajam e se fundem com elementos e modelos existentes nas áreas de destino, criando-se, pois, uma adaptação, tradução em conhecimentos e práticas específicas, ou mesmo um hibridismo de situações (ULTRAMARI, 2012, p. 10).

Verifica-se, portanto, no caso da cobrança da Contribuição de Melhoria no Brasil, uma mescla de formas de transmissão/assimilação de ideias. Primeiramente, a cobrança de fintas no país apenas replicava a prática contida nas Ordenações Filipinas. Num segundo momento, as fintas foram transformadas no tributo Contribuição de Melhoria, assumindo formato especificamente brasileiro, resultante de uma mescla de princípios legais historicamente assimilados.

Entretanto, apesar da longa história do tributo no país, somente recentemente ele vem recebendo atenção por parte das administrações municipais. Isso se deve, principalmente, ao contexto socioeconômico da atualidade, marcado pela escassez de recursos para financiamento do desenvolvimento urbano. Constata-se, assim, que toda a trajetória histórica do 
tributo não tem papel equivalente ao pragmatismo da premência econômica. As ideias assimiladas pela herança portuguesa, e traduzidas em textos legais, somente estão sendo colocadas em prática diante da emergência de recursos para intervenções urbanas.

Séculos de vigência no país; tradição histórica de utilização; existência de normas legais que a referendam, não tem conseguido garantir a consolidação da cobrança da Contribuição de Melhoria. Entretanto, a carência de recursos, frente às demandas do acelerado processo de desenvolvimento urbano, aparece como fator capaz de sensibilizar as administrações públicas para as potencialidades do tributo.

\section{Referências}

BITTENCOURT, M. J. Contribuição de melhoria: realizações sociais. 2012. Disponível em: <:http://www.webartigos.com/artigos/contribuicao-de-melhoria-realizacoes-sociais/43732>. Acesso em: 30 ago. 2012.

BRASIL. Constituição da República dos Estados Unidos do Brasil, de 16 de julho de 1934. Disponível em: <http://www.planalto.gov.br/ccivil_03/constituicao/ constituiçao34.htm>. Acesso em: 4 set. 2012.

BRASIL. Lei Federal n. 10.257, de 10 de julho de 2001. Disponível em: <http://www2.camara.gov.br/legin/fed/ lei/2001/lei-10257>. Acesso em 4 set. 2012.

BRASIL. Senado Federal. Decreto n. 21.390, de 11 de maio de 1932. Disponível em: <http://www6.senado.gov. br/legislacao/ListaTextoIntegral.action?id=18599/>. Acesso em: 28 ago. 2012.

MACHADO, H. B. Curso de Direito Tributário. 28. ed. São Paulo: Malheiros, 2007.

ORDENAÇÕES FILIPINAS. Disponível em: <http://www1. ci.uc.pt/ihti/proj/filipinas/l1ind.htm>. Acesso em: 25 ago. 2012
RIBEIRO, R. V. N. M. Instrumentos fiscais e reabilitação urbana. 2005. 273 f. Dissertação (Mestrado em Planeamento e Projecto do Ambiente Urbano) Faculdade de Engenharia e Arquitectura, Universidade do Porto, Porto, 2005.

SANTIAGO, R. S. A contribuição de melhoria no direito brasileiro: a teoria de seu posicionamento no sistema tributário nacional, 2012. Disponível em: <http://jus. com.br/revista/texto/22144>. Acesso em: 12 ago. 2012.

SILVA, E. N. Contribuição de melhoria. In: MARTINS, I. G. S. (Coord.). Curso de Direito Tributário. 8. ed. São Paulo: Saraiva, 2001. p. 779-792.

SMOLKA, M.; FURTADO, F. Recuperação de mais valias fundiárias urbanas na América Latina: bravura ou bravata? In: SANTORO, P. (Org.) Gestão social da valorização da terra. São Paulo: Instituto Polis, 2005. p. 39-51.

ULTRAMARI, C. A migração das ideias no mundo lusófono: uma investigação sobre a permanência de singularidades urbanas nos territórios de um "mundo". Pontifícia Universidade Católica do Paraná, Curitiba, 2012. (Projeto de Investigação).

VETTER, D.; VETTER, M. Financiamiento basado en el suelo para los municipios brasileños. Land Lines, Oct. 2011. Disponível em: <http://www.lincolninst.edu/ pubs/1971_Financiamiento-basado-en-el-suelo-paralos-municipios>. Acesso em: 2 set. 2012.

Recebido: $15 / 05 / 2012$ Received: 05/15/2012

Aprovado: 22/10/2012

Approved: 10/22/2012 